\title{
A FORMAÇÃO DE PROFESSORES NO PROJETO DE RECONSTRUÇÃO EDUCACIONAL NO BRASIL
}

\author{
Dr. Sidinei Pithan da Silva 0000-0001-6400-4631 \\ Ms. Adriane Helena Dutra Quaresma 0000-0001-9331-4436 \\ Ms. Paula Luiza Pündrich 0000-0002-6256-9492 \\ Universidade Regional do Noroeste do Estado do Rio Grande do Sul
}

\begin{abstract}
RESUMO: Neste artigo buscou-se analisar a escrita do Manifesto dos Pioneiros da Educação Nova (1932) (AZEVEDO, 2006), sob a ótica principal da formação de professores no projeto da reconstrução educacional no Brasil. O objetivo do presente estudo é identificar quais foram as influências do Manifesto de 32 e seus desdobramentos na história da Educação brasileira no que se refere à formação de professores e qual seu legado para a Pedagogia nos dias atuais. O texto foi elaborado com base em pesquisa bibliográfica de autores que abordam a formação social e
\end{abstract}

educacional do Brasil, como Mario Osorio Marques (2006a, b) e Dermeval Saviani et al. (2006). A partir da análise de ações, organizações coletivas e leis sancionadas posteriores à divulgação do Manifesto, e também tendo como referência o PNE (BRASIL, 2015) e as informações atualizadas do Anuário Brasileiro da Educação Básica de 2018, foi possivel visualizar o panorama nacional da educação brasileira, seus avanços e recuos e as implicações tanto para a Pedagogia quanto para a formação e valorização do profissional docente na contemporaneidade.

PALAVRAS-CHAVE: História da Educação; Manifesto dos pioneiros; Formação de professores.

\section{THE FORMATION OF TEACHERS IN THE EDUCATIONAL RECONSTRUCTION PROJECT IN BRAZIL}

\begin{abstract}
In this article, it was sought to analyze the writing of the Manifesto of the Pioneers of New Education (1932) from the main viewpoint of the formation of teachers in the project of educational reconstruction in Brazil. The aim of the present study is to identify what were the influences of the Manifesto of 32 and its unfoldings in the history of Brazilian Education, in what concerns the formation of teachers and what is its legacy for Pedagogy nowadays. The text was elaborated based on a bibliographic research of authors that discuss social and educational formation in Brazil, such as Mario Osorio
\end{abstract}

Marques (2006a; 2006b) and Dermeval Saviani (2006). Based on the analysis of actions, collective organizations and sanctioned laws after the release of the Manifesto, and also taking as references the PNE (BRAZIL, 2014) and the updated information of the Brazilian Yearbook of Basic Education of 2019, it was possible to visualize the national panorama of Brazilian education, its advances and setbacks, and the implications, both for Pedagogy and for the formation and valorization of the teaching professional in contemporary times.

KEYWORDS: History of Education; Pioneers' Manifesto; Teachers' formation. 


\section{Educere "Educare \\ ReVISTA DE EduCAČ̃̃o \\ Programa de Pós-Graduação em Educação - Universidade Estadual do Oeste do Paraná}

\section{INTRODUÇÃO}

O Brasil passou por uma crise de hegemonia politica durante os anos de 20 do século 20. O progresso econômico, social e cultural estava longe de ser uma realidade para as camadas populares do povo brasileiro, pois a falta de políticas educacionais regularizadas pouco permitia o seu desenvolvimento. Segundo dados do IBGE (2000), a taxa de analfabetismo no Brasil, considerando a população de 15 anos ou mais, chegou a $65 \%$ durante esta década, percentual que destaca o descaso e a negligência quanto a planos educacionais necessários para a formação mínima da população, visando o desenvolvimento da sociedade. Em virtude desta defasagem educacional e de incoerências e disputas pelo poder político, houve, nesta década, alguns movimentos que foram influentes no decorrer da história brasileira, como a criação do Partido Comunista, o Movimento Tenentista, a Semana da Arte Moderna e a fundação da Associação Brasileira de Educação (ABE). Dentre as reivindicações presentes, em parte destes movimentos estavam a indignação quanto à hegemonia do poder das oligarquias políticas e a ideia de educação como manutenção da ordem pública.

No âmbito das Conferências Nacionais de Educação e ações da ABE, as ideias quanto à necessidade de reconstrução educacional no país começam a ser pensadas com mais intensidade (MARQUES, 2006a). Neste panorama, a elaboração do Manifesto dos Pioneiros surge como uma alavanca para debates quanto a possiveis mudanças educacionais. A partir deste marco teórico e documental, emerge uma nova projeção para o campo educacional e pedagógico no século 20. Ele torna-se uma referência que continua expressando as relações contraditórias que marcam a sociedade brasileira. No contexto do século 21 , em que as questões em torno dos vínculos entre democracia e educação continuam sendo importantes de serem pensadas, cumpre retomar o lugar que a formação de professores assumiu no Brasil, bem como a própria Pedagogia.

Em nosso entendimento, a proposta de Saviani et al. (2006) e de Marques 


\section{Educere "Educare \\ ReVISTA DE EduCAČ̃̃o}

Programa de Pós-Graduação em Educação - Universidade Estadual do Oeste do Paraná

(2006b) na contemporaneidade, ecoa fortemente o debate e o sentido que a educação assumiu no Brasil com o Manifesto dos Pioneiros (1932) (AZEVEDO, 2006) e, a partir dele, a própria ideia de formação de professores e de um lugar importante para a Pedagogia - como ciência do educador (MARQUES, 2006b). Nesse contexto, se queremos entender porque a Pedagogia é essencial para pensar o ensinar e o aprender na atualidade, torna-se importante revisitar a história da educação no Brasil e, nela, alguns conflitos que estiveram em cena para projetar a educação, a formação de professores e a própria constituição da Pedagogia. O enfoque é feito sob forma de um ensaio, amparado em um pesquisa bibliográfica e documental, com um enfoque crítico e hermenêutico. Nele, ao final, desenvolvemos uma análise sobre as apostas do Plano Nacional de Educação (2014-2024) (BRASIL, 2015), os desafios postos pelo Anuário Brasileiro da Educação Básica (2018), bem como sobre os limites da Base Nacional Comum Curricular - BNCC (BRASIL, 2017).

\section{MANIFESTO DOS PIONEIROS DA EDUCAÇÃO NOVA: ENTRE O DISCURSO E A PRÁTICA DO DEBATE NACIONAL DA FORMAÇÃO DO PROFESSOR}

A elaboração do "Manifesto dos pioneiros da educação nova: a reconstrução educacional do Brasil - ao povo e ao governo", foi idealizada por 26 educadores e intelectuais brasileiros e teve como lideranças Anísio Teixeira, Fernando de Azevedo e Lourenço Filho. Com base em um diagnóstico educacional da época, os signatários do Manifesto evidenciaram que a educação deveria ser a prioridade dos problemas brasileiros a ser resolvida. Os educadores vislumbravam um novo cenário para a educação do país, considerando as teses gerais de laicidade, no qual o Estado seria o agente responsável pela educação nacional, organizando a parte financeira, pedagógica e concepções filosóficas, gratuidade, obrigatoriedade de estudo para as crianças e adolescentes de 7 a 15 anos, e coeducação, na qual meninos e meninas pudessem estudar no mesmo 


\section{Educere "Educare \\ ReVISTA DE EduCAČ̃̃o}

Programa de Pós-Graduação em Educação - Universidade Estadual do Oeste do Paraná

espaço escolar. Além destas teses, o Manifesto enfatiza aspectos biológicos, psicológicos, administrativos e didáticos que influenciam no processo educativo:

Partindo do pressuposto de que a educação é uma função essencialmente pública, e baseado nos princípios de laicidade, gratuidade, obrigatoriedade, co-educação e unicidade da escola, o manifesto esboça as diretrizes de um sistema educacional de educação, abrangendo de forma articulada, os diferentes niveis de ensino, desde a educação infantil até a universidade (SAVIANI et al., 2006, p. 33).

Algumas ideias da "Escola Nova" foram inseridas no Brasil por Rui Barbosa em 1882. As obras originais de Barbosa, que dizem respeito à educação, muitas delas escritas ainda no século 19, praticamente não tiveram repercussão no cenário nacional da época (FARIA FILHO, 2015). Nessa perspectiva, no Brasil os conceitos alavancados pela Escola Nova foram mais influentes na primeira metade do século 20, por meio do educador Anísio Teixeira, que, ao ser aluno de John Dewey em um Curso de Pós-Graduação nos Estados Unidos, tornou-se seu amigo e aliado, e, por isso, muitas das suas ideias, que defendiam a democracia e a liberdade de pensamento como instrumentos para o amadurecimento emocional e intelectual das crianças, foram inspiradas em Dewey (GADOTTI, 2009).

Apenas no século 20, sobretudo depois da década de 40, quando as obras completas foram editadas e publicadas, percebe-se a continuidade das ideias de Rui Barbosa quanto à Escola Nova. Estudos mais detalhados sobre suas obras foram realizados desde então, com alguns deles buscando relacionar o pensamento ruiano com o "protagonismo na introdução da pedagogia moderna no Brasil" (FARIA FILHO, 2015, p. 115).

O Manifesto, que colocou em evidência os princípios da Escola Nova, abre um leque de possibilidades educacionais; dentre as mais importantes está a busca pela oportunidade do acesso das massas populares na escola pública. A desejada coeducação, escola única, precisava ser articulada como um plano que atendesse as demandas educacionais.

A mobilização política dos pioneiros encontrou um embate acirrado com a 


\section{Educere "Educare \\ ReVISTA DE EduCAČ̃̃o}

Programa de Pós-Graduação em Educação - Universidade Estadual do Oeste do Paraná

hegemonia organizativa da Igreja Católica, que não concordava com princípios escolanovistas, principalmente ao se tratar da questão da laicidade, na qual o ensino ficaria desvinculado da educação da igreja. A defesa desta escolarização propõe outro modelo que não fosse o religioso ou o de acesso da população pertencente à classe alta. Neste sentido, haveria um deslocamento de conceitos no processo de ensino. De um lado, a Pedagogia Tradicional caracterizava os conteúdos, como a centralidade do ensino, e, de outro, a renovação pedagógica, por meio da Pedagogia da Escola Nova, que sugeria a valorização das relações entre as pessoas, enfatizando o aluno como centralidade do ensino, valorizando a vivência das experiências e da aprendizagem.

É preciso reconhecer que as mudanças educacionais, ocorridas após a divulgação do referido Manifesto, não são perceptíveis em um primeiro momento, mas, sim, nas reformas educacionais e constituições elaboradas posteriormente. Nessa perspectiva, percebem-se algumas mudanças impulsionadas pelo Manifesto, como a Reforma Universitária, a crescente presença da mulher no trabalho do magistério e a normatização da educação na Constituição de 1934 (BRASIL, 1934).

Como uma das necessidades importantes para a reconstrução educacional do país, o Manifesto destaca a unificação do processo de formação de professores para todos os graus de ensino, visando a não uniformidade, mas multiplicidade. Sobre a preparação de professores, afirmavam os pioneiros que o problema estava na formação universitária, e que, até então, o Ensino Superior no Brasil estava somente a serviço das elites e de algumas formações elitizadas, como engenharia, direito e medicina. Daí a necessidade de uma formação universitária acessivel a todos, sobretudo uma faculdade que formasse o professor para a atuação pedagógica necessária. A realidade do debate sobre as Universidades Brasileiras durante a década de 20 do século 20, constituía-se de um misto de questões politicas e reflexões sobre as funções da Universidade na sociedade (MARTINS, 2002). O fato era que, até a década de 30, a formação de professores que atuavam com o ensino secundário não contava com formação 


\section{Educere Educare \\ ReVISTA DE EduCACÃ̃o}

Programa de Pós-Graduação em Educação - Universidade Estadual do Oeste do Paraná

qualificada em instituições universitárias.

Neste cenário, algumas mudanças referentes à formação de professores foram contempladas na Reforma Universitária, também reconhecida como Reforma Francisco Campos (1931). O decreto instituído dispõe sobre a organização universitária e apresenta a necessidade da formação para os professores que atuariam com o ensino secundário, uma vez que o ensino normal, na época, seria suficiente para a formação dos professores que atuariam de $1^{\text {a }}$ a $4^{\text {a }}$ séries. Segundo Marques (2006a), contudo, na referida Reforma "os cursos de formação pedagógica apresentam caráter à parte, distinto de caráter científico dos demais cursos" (p. 19). Estes estatutos demonstram que a função cultural e científica na formação de professores estava longe de ser prioridade. Ampliando essa visão, o Manifesto previa a unidade na formação dos professores. Segundo o Manifesto dos Pioneiros:

O magistério primário, preparado em escolas especiais (escolas normais), de caráter mais propedêutico, e, às vezes misto, com seus cursos geral e de especialização profissional, não recebe, por via de regra, nesses estabelecimentos, de nível secundário, nem uma sólida preparação pedagógica, nem a educação geral em que ela deve basear-se (AZEVEDO, 2006, p. 200).

O Manifesto defende a formação dos professores em nivel superior, enfatizando a responsabilidade social e a valorização da profissão do magistério. O Manifesto destaca, ainda, que "Todos os professores [...] devem, no entanto, formar o seu espírito pedagógico, conjuntamente, nos cursos universitários, em faculdades ou escolas normais, elevadas ao ensino superior e incorporadas às universidades" (AZEVEDO, 2006, p. 200). Para isso, os renovadores defendiam a necessidade de qualidade na preparação profissional dos professores, mediante formação e remuneração justa e compativel para manter o prestígio indispensável aos educadores.

Outro aspecto interessante, provocado pelo discurso da renovação profissional, foi a ascensão da mulher no trabalho e sua formação diante do quadro educacional do país. A expansão da modernização resultou na evasão de 


\section{Educere "Educare \\ ReVISTA DE EduCAČ̃̃o}

Programa de Pós-Graduação em Educação - Universidade Estadual do Oeste do Paraná

muitas pessoas do setor agrário-rural para o urbano-industrial, e, com isso, percebeu-se a necessidade de um mínimo de instrução para as pessoas que passariam a trabalhar no mercado de trabalho urbano. Este fator levou ao crescimento quantitativo das escolas e à necessidade de professores para reger estas turmas; por conseguinte, aumentou a participação feminina no trabalho, com o crescimento do nível de escolaridade.

Algumas das principais reivindicações dos pioneiros do Manifesto, como a formação dos professores, o princípio de uma escola de caráter pública e gratuita, o Estado enquanto mantenedor dessa escola pública e a expansão do nível superior no Brasil, foram contempladas na Constituição de 1934. O Artigo 148 desta Constituição indica:

Cabe à União, aos Estados e aos Municípios favorecer e animar o desenvolvimento das ciências, das artes, das letras e da cultura em geral, proteger os objetos de interesse histórico e o patrimônio artístico do País, bem como prestar assistência ao trabalhador intelectual (BRASIL, 1934).

Além disso, a referida Constituição ainda estipula responsabilidades competentes à União, como fixar, coordenar e fiscalizar o Plano Nacional de Educação e organizar e manter sistemas educativos apropriados a cada território. Percebe-se, neste Capítulo que versa sobre Educação e Cultura, que as ideias do Manifesto tiveram algum deslocamento do discurso para o teórico, mediante a influência exercida sobre a Constituição de 1934. Seria necessário, ainda, o deslocamento da teoria para a prática.

As medidas fixadas que apontavam para a democratização do ensino no Brasil, resultaram em mudanças perceptiveis, ainda que lentas. Com a obrigatoriedade do ensino primário ${ }^{1}$ e a consequente elevação da quantidade de escolas, houve um salto do número de alunos e professores envolvidos com a educação pública brasileira. Com o aumento da demanda de professores, é indiscutivel que haveria mudanças na sua formação.

Criou-se, em 1935, no Rio de Janeiro (Distrito Federal na época), a

1 O Ensino Primário, nesta época, compreende as turmas de $1^{\mathrm{a}}$ até a $4^{\mathrm{a}}$ série.

Revista Educere Et Educare, Vol. 16. N. 38 (2021) Jan/Abr. 2021. Ahead of Print.

DOI 10.17648/educare.v16i38.24241 


\section{Educere "Educare \\ ReVISTA DE EduCAČ̃̃o}

Programa de Pós-Graduação em Educação - Universidade Estadual do Oeste do Paraná

Universidade do Distrito Federal (UDF), idealizada por Anísio Teixeira. A UDF caracterizou-se pelo fato de, pela primeira vez, ter-se uma Faculdade de Educação, elevando a formação do magistério ao Nível Superior. Em 1939, entretanto, a UDF já foi incorporada à Universidade do Brasil. Percebem-se os indícios de que a formação profissional dos professores em nível superior seria constituída a passos lentos.

No Congresso Brasileiro de Educação Democrática, realizado em 1945, aparece modestamente a abordagem da formação democrática dos professores. Neste contexto da superação do autoritarismo e da busca de caminhos para a redemocratização da sociedade brasileira, é que a questão da formação do educador coloca-se em pauta no cenário de discussão nacional; um debate cada vez mais acirrado em razão da resistência do Poder Executivo em demandar condições dignas para o trabalho docente, e mais qualidade no que diz respeito à formação dos professores (MARQUES, 2006a).

Durante a década de 50 intensificam-se as divergências entre intelectuais católicos e escolanovistas. De um lado, concentravam-se os representantes da Igreja Católica e das elites das escolas privadas, que viam nos ideários da Escola Nova uma ameaça; de outro, estavam, novamente, os defensores da escola pública. Esses debates tiveram destaque importante para a escrita do Manifesto dos Educadores de 1959, intitulado "Mais uma vez convocados: Manifesto ao povo e ao governo". Este Manifesto estampa o cenário educacional do país, retratando que o apelo feito há anos, por intermédio do Manifesto dos Pioneiros, continua apresentando questões muito atuais para a época, como a defesa de uma política nacional de educação e escola pública obrigatória, gratuita e mantida pelo Estado.

Logo após o Manifesto, foi sancionada a Lei $\mathrm{N}^{\circ} 4.024$, de 20 de dezembro de 1961, que Fixa as Diretrizes e Bases da Educação Nacional. Percebe-se nela alguma influência do Manifesto dos Pioneiros, como o fato de a educação ser um direito de todos. Fica em evidência, no entanto, o direito reservado para as escolas privadas trabalharem com autonomia, respeitando as diretrizes gerais. 


\section{Educere Educare \\ ReVISTA DE EduCACÃ̃o}

Programa de Pós-Graduação em Educação - Universidade Estadual do Oeste do Paraná

Quanto à formação dos professores, a Lei de Diretrizes e Bases (LDB) 4.024/61, em seu Capítulo IV, Da Formação do Magistério para o Ensino Primário e Médio, cita:

Art. 53: A formação de docentes para o ensino primário far-se-á:

a) em escola normal de grau ginasial no mínimo de quatro séries anuais onde além das disciplinas obrigatórias do curso secundário ginasial será ministrada preparação pedagógica;

b) em escola normal de grau colegial, de três séries anuais, no mínimo, em prosseguimento ao vetado grau ginasial.

Art. 59. A formação de professores para o ensino médio será feita nas faculdades de filosofia, ciências e letras e a de professôres de disciplinas específicas de ensino médio técnico em cursos especiais de educação técnica (BRASIL, 1961).

Percebe-se, assim, que a questão da formação de professores e o próprio lugar da Pedagogia, ainda permaneciam com pouco destaque. A subscrita LDB de 1961 evidencia o direito à educação, porém uma educação de qualidade perpassa também pela qualidade de formação de seus professores, mas esse fato ainda é pouco considerado na época.

Historicamente, o Brasil passou por um periodo de crise da democracia, que se manifesta entre os anos de 1964-1985. De forma particular, com o declínio da ditadura militar, iniciado com a posse de Geisel em 1974 até o término do governo de Figueiredo em 1985 ocorrem algumas mudanças na educação. Mesmo com certa repressão política da época, surgiram várias associações, como a Associação Nacional de Educação (Ande), a Associação Nacional de Pós-Graduação em Educação (Anped), os Centros Estaduais de Professores, o Centro de Estudos Educação e Sociedade (Cedes) e o Centro de Estudos de Cultura Contemporânea (Cedec). Foi em Salvador, durante uma reunião da Anped, na qual também se faziam presentes representantes da Ande e do Cedes, que emergiu a proposta da I Conferência Brasileira de Educação (CBE), posto que havia confluências de ideias quanto à questão das políticas educacionais do país.

Desta forma, em 1980, na cidade de São Paulo, reunindo mais de 1.400 profissionais e estudantes de diferentes áreas da educação, realizou-se a I 


\section{Educere Educare \\ ReVISTA DE EduCAČ̃̃o}

Programa de Pós-Graduação em Educação - Universidade Estadual do Oeste do Paraná

Conferência Brasileira de Educação, tendo como temas centrais a Educação Popular, a Pré-Escola, o $1^{\circ}$ Grau, o $2^{\circ}$ Grau, o Ensino Público, o Ensino Superior, a Associação de Docentes e a Educação Democrática. Segundo o Boletim da ANPEd, a I Conferência Brasileira de Educação representou "importante marco na sua busca de uma atuação mais decisiva na avaliação crítica da política educacional e na procura de novos rumos para a educação do país" (BOLETIM ANPEd, 1980).

Durante a I Conferência Brasileira de Educação, foi instituído o Comitê Nacional Pró-Formação do Educador, visando a aprimorar os cursos de formação do educador. Em consonância, o MEC reativou estudos que objetivavam subsidiar o Conselho Federal de Educação na reformulação dos cursos de Pedagogia e demais Licenciaturas. Percebe-se que:

Na década dos anos 80, o acontecimento central da educação brasileira é a presença coletiva organizada dos professores, pela afirmação do caráter profissional do trabalhador em educação, melhores condições de trabalho, gestão democrática e escola de qualidade para todos (MARQUES, 2006a, p. 25).

Alavancados pela I CBE, são realizados outros eventos em âmbito nacional, nos quais gradativamente se reforçou a preocupação pela fundamentação científica da formação do educador, trazendo para as universidades essa responsabilidade. Seguindo com base nesses princípios, os Encontros Nacionais subsequentes deram ênfase à continuidade do movimento de reformulação da Pedagogia e dos cursos de formação de educadores. Os mesmos trouxeram à tona o tema Base Nacional Comum, como tentativa de superação da fragmentação e desarticulação, e o Projeto da Lei de Diretrizes e Bases (MARQUES, 2006a).

Seguindo o percurso histórico, percebe-se que na elaboração da Constituição da República Federativa do Brasil de 1988, foram descritos alguns aspectos elencados como prioridade pelos pioneiros do Manifesto de 32, como a questão do financiamento da educação pelo Estado (com o aumento dos percentuais minimos de investimento), liberdade de aprender, ensinar, 


\section{Educere "Educare \\ ReVISTA DE EduCAČ̃̃o}

Programa de Pós-Graduação em Educação - Universidade Estadual do Oeste do Paraná

pesquisar, divulgar o pensamento, a arte, o saber e preparar cada pessoa para o exercício da cidadania e qualificação para o trabalho. Somente em leis posteriores, como a Lei de Diretrizes e Bases da Educação Nacional de 1996 e o Plano Nacional da Educação, contudo, a formação democrática dos profissionais da educação tornou-se mais evidente.

\section{O LEGADO DO MANIFESTO E OS DESAFIOS ATUAIS}

O Manifesto dos Pioneiros (1932) (AZEVEDO, 2006) engrandece o exercício dos direitos dos cidadãos brasileiros quanto à educação. Destacamos, aqui, a educação com função essencialmente pública, sob a responsabilidade do Estado, a escola única, a laicidade, a gratuidade e a obrigatoriedade da educação. No que se refere à formação dos professores, os pioneiros reivindicavam ações na reestruturação da formação da época em nível superior, assim como melhores condições de trabalho e salários condizentes com suas funções docentes.

É pertinente relembrar que, segundo os autores do Manifesto, esta é a primeira iniciativa no sentido de compreender que a formação do educador deveria ser diferenciada, em razão, principalmente, do contexto social e político da época, que reclamava uma nova educação.

Neste sentido, era imprescindível para o exercício da função educativa a formação em nível superior dos professores como um fator de alavancar a cultura geral, sanar as injustiças sociais e estabelecer os princípios de igualdade e unidade nacional. Por intermédio do Manifesto da Escola Nova, nascia uma nova política educacional, com destaque na formação do profissional da educação, marcada pelas influências econômicas, industriais, científicas, políticas e intelectuais atuantes na época.

Sendo assim, as reformas educacionais evidenciadas no Manifesto dizem respeito à preocupação com a formação pedagógica e unificada dos professores, reivindicando, portanto, a reforma universitária para a "Reconstrução 


\section{Educere "Educare \\ ReVISTA DE EduCAČ̃̃o}

Programa de Pós-Graduação em Educação - Universidade Estadual do Oeste do Paraná

Educacional".

Com o passar dos anos, perceberam-se significativas mudanças e grandes avanços que o Manifesto proporcionou em alguns aspectos desde então. É preocupante perceber, contudo, que a questão que se refere à formação do profissional da educação ainda está longe de ser a tão desejada reforma. Alguns dos entraves que vivenciamos hoje, como a carência de professores de algumas áreas, vêm da falta de gestão pública e de planejamento estratégico da política de formação profissional para a educação. É pertinente destacar, ainda, que alguns dos principais problemas apontados pelo Manifesto, como a qualidade do ensino, dependem, em grande parte, da formação e remuneração equivalente à sua formação. Tal problema em torno da valorização docente, que possibilite ao profissional da educação um trabalho digno e eficiente, continua atual e na ordem do dia, para que ele possa exercer sua função no ensino e na educação de forma efetiva e com qualidade social e democrática.

Atualmente, a Lei de Diretrizes e Bases da Educação Nacional - LDB (BRASIL, 1996) define a obrigatoriedade da formação inicial em nivel superior. Após um tempo considerável da aprovação da LDB/96, no entanto, a carreira do professor segue desvalorizada: uma parte considerável dos docentes não têm acesso a uma formação inicial de qualidade e/ou continuada, e alguns Estados brasileiros não pagam sequer o piso salarial, cujo valor já vem defasado há muitos anos.

De acordo com Souza (2015), "é possivel visualizar que parte significativa dos estados brasileiros elaborou leis que normatizaram a carreira e a remuneração docente". Souza (2015, p. 55), enfatiza, contudo, que muitos deles enfrentam dificuldade no cumprimento de algumas diretrizes, sobretudo em relação à valorização do profissional docente.

Esta questão é também explicitada pela Constituição da República Federal do Brasil de 1988 (BRASIL, 1988), em seu artigo 206, incisos V e VIII; quando trata da Educação, a mesma garante a valorização dos profissionais da educação e plano de carreira com piso salarial para os profissionais da educação pública. 


\section{Educere "Educare \\ ReVISTA DE EduCACÃ̃o \\ Programa de Pós-Graduação em Educação - Universidade Estadual do Oeste do Paraná}

Neste sentido, Souza (2015) afirma que

Fica evidente, portanto, que estes foram os importantes desdobramentos para a educação nacional, uma vez que todas as determinações se nortearam por politicas públicas traduzidas pelo acesso e permanência à educação básica, em que a valorização dos profissionais da educação é um dos condicionantes para se alcançar uma educação de qualidade (SOUZA, 2015, p. 60).

Cuidar dos programas de formação de professor e da valorização profissional, como explicitado neste texto anteriormente, é uma das principais medidas governamentais para a melhoria da qualidade da educação e do ensino. Fazendo referência à LDB (BRASIL, 1996), o artigo 61, que se ocupa da formação dos profissionais da educação, estabelece que a finalidade da mesma é "atender aos objetivos dos diferentes níveis e modalidades de ensino e às características de cada fase de desenvolvimento do educando". Garante, inclusive, que a formação deve ser executada, segundo a mesma Lei, "mediante capacitação em serviço" e "o aproveitamento da formação e experiências anteriores", até mesmo as experiências adquiridas em instituições que não são de ensino, mas que possuem "outras atividades".

Seguindo nesta mesma linha, a Resolução do Conselho Nacional de Educação e da Câmara de Educação Básica (CNE/CEB) n 2/2009, baseada no Parecer CNE/CEB n ${ }^{\circ}$ 9/2009, que se ocupa da carreira do profissional docente, determina um conjunto de normas com destaque na valorização dos profissionais da educação, que resultam na sua qualidade.

De acordo com as Diretrizes Curriculares Nacionais gerais para a Educação Básica (BRASIL, 2013), "as politicas de formação dos profissionais da educação [...] são orientações cujo objetivo central é o de criar condições para que seja possível melhorar o desempenho das escolas, mediante ação de todos os seus sujeitos" (p. 15).

Seguindo o que preconiza as Diretrizes Curriculares Nacionais - DCNs (BRASIL, 2013):

Os sistemas de ensino promoverão a valorização dos profissionais da 


\section{Educere "Educare \\ ReviSTA De EduCAC̄̃̃o \\ Programa de Pós-Graduação em Educação - Universidade Estadual do Oeste do Paraná}

educação, assegurando-lhes, inclusive nos termos dos estatutos e dos planos de carreira do magistério público:

I - ingresso exclusivamente por concurso público de provas e títulos;

II - aperfeiçoamento profissional continuado, inclusive com licenciamento periódico remunerado para esse fim;

III - piso salarial profissional;

IV - progressão funcional baseada na titulação ou habilitação, e na avaliação do desempenho;

$\mathrm{V}$ - período reservado a estudos, planejamento e avaliação, incluído na carga de trabalho;

VI - condições adequadas de trabalho (art. 67).

O Plano Nacional da Educação (BRASIL, 2015), um documento com 20 metas, que tem como objetivo orientar esforços e investimentos visando àmelhor qualidade da educação em âmbito de território nacional, foi aprovado em 26 de junho de 2014, com vigência de dez anos, que compreendem os anos de 2014 a 2024. Da Meta 15 até a Meta 18 é tratado a respeito da formação inicial e continuada dos profissionais da educação, da valorização e equiparação salarial, do plano de carreira e do piso salarial nacional.

Meta 15 - Garantir em regime de colaboração entre a União, os Estados o Distrito Federal e os Municípios, no prazo de 1 (um) ano de vigência deste PNE, política nacional de formação dos profissionais da Educação de que tratam os incisos I, II e III do Caput do art. 61 da lei $\mathrm{N}^{\circ} 9.394$ de 20 de dezembro de 1996, assegurado que todos os professores e as professoras da Educação Básica possuam formação específica de nível superior, obtida em curso de licenciatura na área de conhecimento em que atua.

Meta 16 - Formar, em nível de pós-graduação, 50\% (cinquenta por cento) dos professores da Educação Básica, até o último ano de vigência deste PNE, e garantir a todos (as) os (as) profissionais da Educação Básica formação continuada em sua área de atuação, considerando as necessidades, demandas e contextualizações dos sistemas de ensino.

Meta 17 - Valorizar os (as) profissionais do magistério das redes públicas de Educação Básica de forma a equiparar seu rendimento médio ao dos (as) demais profissionais com escolaridade equivalente, até o final do sexto ano de vigência deste PNE.

Meta 18 - Assegurar, no prazo de dois (dois) anos, a existência de planos de Carreira para os (as) profissionais da Educação Básica e Superior pública de todos os sistemas de ensino e, para o plano de Carreira dos (as) profissionais da Educação Básica pública, tomar como referência o piso salarial nacional profissional, definido em lei federal, nos termos do inciso VIII do art. 206 da Constituição Federal (BRASIL, 2015).

Fazendo um resumo em âmbito de Brasil, tendo como base os dados referentes ao ano anterior à criação do PNE, 2013, em referência à Meta 15, o número de professores que possuía formação em nível de Educação Superior era 


\section{Educere "Educare \\ ReVISTA DE EduCAČ̃̃o}

Programa de Pós-Graduação em Educação - Universidade Estadual do Oeste do Paraná

de $74,8 \%$, segundo informações do Anuário Brasileiro da Educação Básica de 2018.

Nesta atualização dos dados para a Meta 15, o Anuário Brasileiro da Educação Básica de 2018 apresenta, no ano de 2018, um percentual de 79,9\%, um tímido avanço de 5,1\%, considerando que já se passaram cinco anos de vigência do PNE e que o mesmo estabelece e assegura que "todos" os professores devem ter formação em nível superior.

Estes resultados apresentados nos mostram um panorama distante daquele definido pelo PNE e expressam a necessidade de avançar neste sentido, com políticas públicas de formação que atendam a esta demanda. É notório que a formação docente é uma das medidas fundamentais para garantir a qualidade na educação. O Anuário Brasileiro da Educação Básica de 2018 revela que os desafios quanto a este tema são gigantes, e requer-se pensar em mudanças e estratégias no ensino brasileiro com urgência prioritária.

Quanto à Meta 16 do PNE, que trata da formação continuada em nível de Pós-Graduação, observa-se que em 2013, levando em consideração a Educação Básica em âmbito de país, o índice era de 30\%, e no ano de 2018 foi de 36,9\% (ANUÁRIO..., 2018, p. 105). Tendo como referência o ano de efetivação do PNE 2014 -, e considerando que a meta é que 50\% dos profissionais da educação tenham formação em nível de Pós-Graduação, e, decorridos metade do tempo estipulado para atingir este objetivo, é possivel perceber que, mesmo com um aumento de pouco mais de $6 \%$, esta meta está longe de ser atingida e faz-se necessário que se tome medidas iminentes para o cumprimento da mesma.

Segundo informações do Observatório do PNE, a Meta 16 é analisada sob dois aspectos: 16a e 16b. A primeira (16a) refere-se à formação dos professores da Educação Básica com Pós-Graduação. Tem por objetivo que $50 \%$ dos profissionais da educação tenham essa formação até o final deste PNE (BRASIL, 2015). Esse tem vigência nos anos de 2014 até 2024. Os dados atuais (novembro/2019) apontam o percentual de $36,2 \%$ do cumprimento da mesma. $\mathrm{Na}$ segunda (16b), que se reporta a professores da Educação Básica com 


\title{
Educere Educare \\ ReVISTA DE EduCACÃ̃o
}

Programa de Pós-Graduação em Educação - Universidade Estadual do Oeste do Paraná

formação continuada, o observatório mostra uma distância ainda mais expressiva para efetivação da mesma, pois dos $100 \%$ que se estabeleceu como meta até 2024, apenas 35,1\% dela foi alcançada até esta data (novembro/2019).

A análise realizada quanto à Meta 17 , que diz respeito à valorização dos profissionais docentes, com certeza assinala um dos desafios fundantes para a melhoria na qualidade da educação brasileira, como já mencionamos anteriormente. Assim está expresso no PNE (BRASIL, 2015):

\begin{abstract}
É possivel afirmar que a valorização do magistério perpassa diversas dimensões, como a formação adequada e contínua, a estruturação de carreiras, as condições apropriadas de trabalho e a constituição de patamares adequados de remuneração. Nesse contexto, o objetivo central da Meta 17 consiste em equiparar o rendimento médio dos profissionais do magistério ao dos demais profissionais com escolaridade equivalente. Cabe ressaltar que o amplo debate sobre a valorização dos profissionais do magistério tem como precedente os baixos salários praticados na remuneração de professores da educação básica pública em grande parte dos estados e municípios da Federação, em comparação com demais profissionais de escolaridade similar (p. 287-288).
\end{abstract}

Segundo informações atualizadas pelo Anuário Brasileiro da Educação Básica de 2018, é possível constatar, pelo que está exposto, que em 2013 o rendimento médio dos professores da Educação Básica, em comparação com outros profissionais de outras áreas com curso superior, era de 65,3\%. Em dezembro de 2018, este percentual teve um sutil aumento para 69,8\%. É relevante considerar, contudo, que tais dados incluem a rede pública e privada.

Estes dados são preocupantes, sobretudo se levar em conta que já se passaram cinco anos da aprovação do PNE (BRASIL, 2015) e que a meta visa à equiparação salarial docente até o final do sexto ano de vigência do mesmo. Resta pouco tempo para o muito que precisa ser feito para a tão almejada meta ser alcançada.

Cabe ressaltar, também, que, de acordo com o PNE (BRASIL, 2015), o real cumprimento da Meta 17 está intrinsecamente ligado à execução da Meta 18, a qual visa a garantir, em dois anos de vigência do PNE, a instituição de planos de 


\section{Educere "Educare \\ ReVISTA DE EduCAČ̃̃o}

Programa de Pós-Graduação em Educação - Universidade Estadual do Oeste do Paraná

carreira para os profissionais da educação básica, tendo como referência o piso salarial nacional definido em lei federal.

De acordo com o Anuário Brasileiro da Educação Básica de 2018, "cerca de $10 \%$ dos municípios, por exemplo, ainda não têm plano de carreira para seus professores (p. 111)", dados estes que evidenciam o enorme desafio de um sistema escolar em um país que reproduz inúmeras desigualdades sociais e que requer, urgentemente, políticas públicas e reformas educacionais que promovam mais equidade e justiça social.

A Base Nacional Comum Curricular (BRASIL, 2017) afirma que as mudanças provocadas pela mesma, entre outros fatores, influenciam na formação inicial e continuada dos profissionais da educação, de forma a "manter processos permanentes de formação docente que possibilitem contínuo aperfeiçoamento dos processos de ensino e aprendizagem" (BRASIL, 2017, p. 17), convergindo para uma educação de qualidade, com menos desigualdades, que possibilitem avanços educacionais no país.

Em relação à BNCC (BRASIL, 2017), no entanto, Silva (2018) chama atenção para as questões assinaladas pelo documento quanto à melhoria da qualidade na educação, ressaltando a necessidade de um "pacto interfederativo" para angariar recursos financeiros para Estados e municipios

[...] para além de apenas formação técnica de equipes gestoras, leia-se elaboradoras da parte diversificada, e inspetoras quanto ao monitoramento das práticas docentes. A realidade das escolas e a qualidade do ensino público vão além das questões curriculares, e são perpassadas por aspectos relacionados à remuneração e formação docente, infraestrutura, equipamentos e materiais didáticos em condições e quantidades adequadas, atendimento especializado para alunos com deficiência ou superdotação, número de alunos por sala, etc. Diante disso, percebe-se que esta reforma curricular, de caráter conteudista, disciplinar, pragmática, alicerça-se na premissa de que se o aluno não aprende é porque a escola não ensina, mas não se consideram as fragilidades do sistema educativo como um todo (SILVA, 2018, p. 140).

Neste sentido, cabe destacar que os rumos da educação, na perspectiva da qualidade assinalada pela BNCC (BRASIL, 2017), seguem uma lógica de mercado, econômica, visando à lucratividade, articulada com uma engrenagem 


\section{Educere "Educare \\ ReVISTA DE EduCAČ̃̃o}

Programa de Pós-Graduação em Educação - Universidade Estadual do Oeste do Paraná

com cenário internacional, voltado a determinadas etapas da escolarização. Silva (2018) nos faz notar que "uma política pública educacional hegemônica, como propõe a BNCC, não tem plenas condições de gerir universos de aspectos que se articulam de modos diferenciados em cada escola" (p. 145), levando-se em consideração as particularidades de cada contexto e sala de aula.

\section{CONSIDERAÇÕES FINAIS}

É notório que para empreender o projeto de reconstrução da educação brasileira no cenário do século 21, faz-se necessário assentar bases sólidas na formação docente continuada, na valorização da qualificação do profissional e nos saberes e conhecimentos do professor. Os dados do Anuário Brasileiro da Educação Básica (2018), que sinalizam os déficits e os desafio para o investimento na educação e na formação de professores, indicam o quanto é preciso para concretizar as metas do Plano Nacional de Educação (2014-2024) (BRASIL, 2015).

É inadiável que haja um diálogo para o enfrentamento desta problemática, considerando as experiências dos docentes, imprescindiveis na formação e no fortalecimento da identidade profissional docente, sempre pensando na promoção da educação de qualidade em perspectiva emancipatória. Marques (2006b) enfatiza que o exercício da docência abre possibilidades de diálogo ante os desafios da reconstrução das formações de professores com ações efetivas para a profissionalização destes, alicerçada na construção dos saberes da experiência docente enquanto ensinantes e aprendizes. Segundo Marques (2006b), torna-se importante assumir a Pedagogia como ciência do Educador.

Entendemos, neste contexto assinalado, que, para o exercício da profissão de professor, é preciso ter, necessariamente, Formação Pedagógica, embasamento teórico, conhecimento e senso crítico. Se não tiver essa compreensão, o professor torna-se ativista, executor de ações planejadas por 


\section{Educere "Educare \\ ReVISTA DE EduCAČ̃̃o \\ Programa de Pós-Graduação em Educação - Universidade Estadual do Oeste do Paraná}

outros, e faz sempre a mesma coisa, sem refletir sobre sua ação docente. $\mathrm{O}$ enfoque específico e especial sobre a Pedagogia, como dimensão central de todos aqueles que se ocupam da educação, implica assumir que ela reivindica um corpo próprio de conhecimentos, os quais permitem uma reflexividade ampliada sobre o problema do saber/conhecimento, da educação e da condição humana, em sentido social, cultural e histórico.

Os vínculos que aqui estabelecemos com a constituição da educação no Brasil, explicitam o próprio compromisso da Pedagogia: ser uma ciência que, em interface com outras ciências, possui autonomia para expressar sentidos ampliados, com vínculos éticos e políticos. Isso torna-se ainda mais relevante quando a própria configuração histórica acerca das perspectivas democráticas e emancipatórias no Brasil, são questionadas diante de um pensamento populista, conservador e autoritário que emerge no século 21. Retomar o Manifesto de 32 e o sentido de constituição de um Povo Nação, que aspira a liberdade e objetiva questionar as opressões que historicamente foram estabelecidas no Brasil pelas elites, é um marco civilizatório importante para a continuidade da República e da Democracia.

Os debates sinalizados pelos documentos nacionais no século 21 , à luz da Constituição Brasileira (BRASIL, 1988), da LDB (BRASIL, 1996), das DCNs (BRASIL, 2013) e do PNE (BRASIL, 2015), sinalizam para desafios crescentes em relação à formação de professores que fazem lembrar as apostas do Manifesto de 32 quanto aos ideias democráticos. A BNCC (BRASIL, 2017), sob o pano de fundo de sua apresentação, aparece no mesmo movimento, mas, ao centrar e concentrar seu apelo à questão curricular, sem considerar as fragilidades do sistema (SILVA, 2018), tampouco ao caráter contextual que implica as condições de trabalho dos professores, sofre uma dura crítica. Para participar de tal movimento de crítica e construção da educação no Brasil, tanto na sala de aula quanto nos espaços ampliados da sociedade, é fundamental que os professores tenham pensamento pedagógico próprio, para concretizar a democracia no Brasil em seu vínculo com a liberdade, a justiça social e a dignidade humana. 


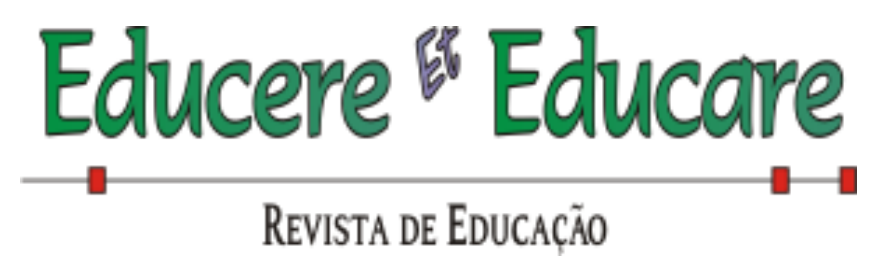

Programa de Pós-Graduação em Educação - Universidade Estadual do Oeste do Paraná

\section{REFERÊNCIAS}

ANUÁRIO BRASILEIRO DA EDUCAÇÃO BÁSICA. São Paulo: Ed. Moderna, 2018. Disponivel em: http://www.moderna.com.br. Acesso em: 31 out. 2019.

AZEVEDO, Fernando. O manifesto dos pioneiros da Educação Nova (1932): a reconstrução educacional no Brasil ao povo e ao governo. Revista HISTEDBR On-Line, Campinas, n. especial, p. 188-204, ago. 2006.

BOLETIM ANPEd. v. 2, n. 1. jan./mar. 1980. Disponivel em: http://www.anped.org.br/sites/default/files/boletim_anped_v._2_n.1.pdf. Acesso em: 30 out. 2019.

BRASIL. Constituição da República dos Estados Unidos do Brasil. Rio de Janeiro, 1934. Disponivel em:

http://www.planalto.gov.br/ccivil_03/constituicao/constituicao34.htm. Acesso em: 26 out. 2019.

BRASIL. Lei $\mathrm{n}^{\circ}$ 4.024, de 20 de dezembro de 1961. Fixa as diretrizes e bases da educação nacional. Lei de Diretrizes e Bases da Educação - LDB. Brasília, DF, 1961. Disponivel em: http://wwwp.fc.unesp.br/ lizanata/LDB\%204024-61.pdf. Acesso em: 5 nov. 2019.

BRASIL. Constituição da República Federal do Brasil. Brasília, DF: Senado Federal, 1988. Disponivel em:

http://www.planalto.gov.br/ccivil_03/constituicao/constituicaocompilado.htm. Acesso em: 26 out. 2019.

BRASIL. Ministério da Educação e do Desporto. Lei de Diretrizes e Bases da Educação Nacional. Lei n. 9.394 de 20 de dezembro de 1996. Brasília: MEC, 1996.

BRASIL. CNE. CEB. Parecer CNE/CEB n 9 de 2 de abril de 2009. Diretrizes para os Novos Planos de Carreira e de Remuneração para o Magistério dos Estados, do Distrito Federal e dos Municipios. Brasília, 2009a. Disponível em: http://portal.mec.gov.br/dmdocuments/pceb009_09.pdf. Acesso em: 15 nov. 2019. 


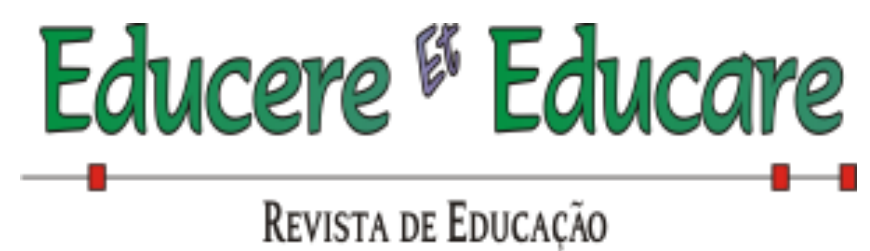

Programa de Pós-Graduação em Educação - Universidade Estadual do Oeste do Paraná

BRASIL. CNE. CEB. Resolução n. 2, de 22 de maio de 2009. Fixa as Diretrizes Nacionais para os Planos de Carreira e Remuneração dos Profissionais do Magistério da Educação Básica Pública. Brasília: 2009b. Disponivel em: http://portal.mec.gov.br/dmdocuments/resolucao_cne_ceb002_2009.pdf. Acesso em: 15 nov. 2019.

BRASIL. Ministério da Educação. Diretrizes Curriculares Nacionais Para Educação Básica. Brasília: MEC; SEB; Dicei, 2013.

BRASIL. Instituto Nacional de Estudos e Pesquisas Educacionais Anisio Teixeira. Plano Nacional de Educação PNE 2014-2024: Linha de Base. Brasília, DF: Inep, 2015. Disponivel em: http://portal.inep.gov.br/informacao-dapublicacao/-/asset_publisher/6JYIsGMAMkW1/document/id/493812 Acesso em: $1^{\circ}$ nov. 2019.

BRASIL. Base Nacional Comum Curricular: Educação Infantil e Ensino Fundamental. Brasília: MEC; Secretaria de Educação Básica, 2017.

FARIA FILHO, Luciano Mendes de. Os sentidos da renovação educacional: ecos do debate sobre a escola nova na edição e apropriação de Rui Barbosa na década de 1940. Revista Brasileira de Estudos Pedagógicos, Brasília, v. 96, n. especial, p. 113-131, 2015.

GADOTTI, Moacir. O pensamento pedagógico brasileiro. 8. ed. rev. São Paulo: Ática, 2009.

IBGE. Instituto Brasileiro de Geografia e Estatística. Censo Demográfico, 2000.

MARQUES, Mario Osorio. A formação do profissional da educação. 5. ed. rev. Ijuí: Editora Unijuí, 2006a.

MARQUES, Mario Osorio. Pedagogia: a ciência do educador. 3. ed. rev. Ijuí: Editora Unijuí, 2006b.

MARTINS, Antonio Carlos Pereira. Ensino Superior no Brasil: da descoberta aos dias atuais. Acta Cir. Bras., São Paulo, v. 17, suppl. 3, 2002. ISSN 1678-2674. Disponivel em: http://dx.doi.org/10.1590/S0102-86502002000900001. Acesso em: 3 nov. 2019.

OBSERVATÓRIO do PNE. Disponivel em: https://www.observatoriodopne.org.br. Acesso em: 3 nov. 2019.

SAVIANI, Dermeval et al. (org.). O legado educacional do século XX no Brasil. 2. ed. Campinas: Autores Associados, 2006. 


\section{Educere Educare \\ ReVISTA de EducAC̄̃o}

Programa de Pós-Graduação em Educação - Universidade Estadual do Oeste do Paraná

SILVA, Vanessa Silva da. Base Nacional Comum Curricular: uma análise crítica do texto da política. 2018. Dissertação (Mestrado) - Universidade Federal de Pelotas, Programa de Pós-Graduação em Educação, Faculdade de Educação, Pelotas, 2018. Orientadora Maria de Fátima Cóssio.

SOUZA, Jeferson Mello. A construção da carreira docente no sistema municipal de ensino de Rio Claro: profissionalização e valorização profíssional. Rio Claro, 2015. Dissertação (Mestrado) - Universidade Estadual Paulista, Instituto de Biociências de Rio Claro, Rio Claro, 2015. Orientadora Joyce Mary Adam.

Recebido em: 27/07/2020 Aceito em: 18/02/2021 